\title{
Prevalence and Determinants of Chest-Related Symptoms of Acute Respiratory Tract Infections among Children below 5 Years in Upper Egypt
}

\author{
Ahmed El-Abd Ahmed ${ }^{1 *}$, Ekram M Abdel Khalek ${ }^{2}$ and Ahmed H Kamel Marzok
}

${ }^{1}$ Department of Pediatric, South Valley University, Qena, Egypt

${ }^{2}$ Department of Public Health and Community Medicine, Faculty of Medicine, Assiut University, Egypt

${ }^{3}$ Department of Resident doctor in Pediatric, Assiut Mabara Hospital, Egypt

\begin{abstract}
Background: Acute respiratory infection is an infection that affects children younger than 5 years from 3 to 8 episodes per year.
\end{abstract}

Aim of the Study: Identification the prevalence of chest-related ARI symptoms among children less than 5 years in Upper Egypt and its determinants.

Methods: The Secondary analysis was done based on data sets of Egypt Demographic Health Survey (DHS) 2008 targeting 4,745 children living in Upper Egypt Governorates.

Results: The present study included 4,745 children less than 5 years in Upper Egypt who included in DHS 2008 with the mean age 28.27 months. It was found that 891 suffered from a cough during the two-week period before the DHS survey with a prevalence of $18.8 \%$. Less than three quarters of them had experienced short or rapid breathing because of a problem in the chest or/and the nose. Children aged 6 to 23 months and male children were the most likely had chest related acute respiratory tract infection symptoms.

Conclusion: Children aged 6 to 23 months and male children were the most likely had the symptoms.

Keywords: Chest-related symptoms; Acute respiratory infectionunder 5 children

\section{Introduction}

Acute respiratory infection (ARI) begins as a viral infection in the nose, trachea or lungs. If it is not treated, it can spread to the respiratory system as whole [1]. World Health Organization (WHO) defined ARI as "a clinical state presenting with rapid breathing more than expected upper limit for age with or without chest in drawing, too sick to feed, nasal discharge, cough, fever with or without auscultatory findings of less than 2 weeks". ARIs incidence is high among infants, children, and the elderly and is more pronounced in low- and middle-income middleincome countries [2]. In developing countries ARIs are considered the major causes of under-five children mortality and morbidity [3-5]. Many studies concluded that acute respiratory infections were significantly related to the child age, family size, immunization and breastfeeding status [6-8]. According to Demographic Health Survey (DHS) more than one-quarter of Egyptian children below five years suffered from cough 15 days ago of the survey; $14 \%$ had cough with short, rapid, or difficult breathing that was chest-related [9]. In the primary health care, pneumonia is recognized based on two simple clinical findings: fast breathing and chest in drawing [10]. Physicians rely on the child caregiver to recognize cough or difficult breathing [11].

\section{Aims of the study}

- Identification of chest-related acute respiratory tract infection symptoms prevalence among children below 5 years in Upper Egypt

- Determination of the relation between different sociodemographic factors and chest related ARI symptoms among the target group

\section{Materials and Methods}

\section{Study setting}

Governorate of Upper Egypt.

\section{Study subjects}

Children aged less than 5 years in Upper Egypt included in Egypt Demographic Health Survey (EDHS)-2008.

\section{Study design}

Secondary analytical study based on data sets of EDHS-2008 was carried out. EDHS-2008 is the ninth in a series of demographic and health surveys conducted in Egypt.

\section{Sample size}

Nationally representative DHS sample included 4,745 children aged less than 60 months.

\section{Instruments used}

Household and individual-level data from the Demographic and Health Surveys (DHS) program were used. Information on the prevalence of ARI was collected in the 2008 EDHS by asking mothers of children three questions to identify children who had cough in the two weeks before the survey. For the children who had cough, a second question was asked to determine if the child had short rapid breaths or had difficulty in breathing.

*Corresponding author: Ahmed El-Abd Ahmed, Department of Pediatric South Valley University, Qena, Egypt, Tel: 01003329944/01115069895; E-mail: Yasen112010@gmail.com

Received May 17, 2016; Accepted August 29, 2016; Published August 31, 2016 Citation: El-Abd Ahmed A, Abdel Khalek EM, Kamel Marzok AH (2016) Prevalence and Determinants of Chest-Related Symptoms of Acute Respiratory Tract Infections among Children below 5 Years in Upper Egypt. J Pulm Respir Med 6 : 366. doi: 10.4172/2161-105X.1000366

Copyright: () 2016 El-Abd Ahmed A, et al. This is an open-access article distributed under the terms of the Creative Commons Attribution License, which permits unrestricted use, distribution, and reproduction in any medium, provided the original author and source are credited. 
If the mother indicated that the child had experienced fast or difficult breathing, they were asked whether it was the result of a problem in the chest or a blocked or runny nose.

The wealth index is a composite measure of a household's cumulative living standard. The wealth index is calculated using easyto-collect data on a household's ownership of selected assets, such as televisions and bicycles; materials used for housing construction; and types of water access and sanitation facilities.

\section{Operational definition}

Cough accompanied by short, rapid breathing that is chest-related is considered symptoms of pneumonia [12].

\section{Ethical considerations}

Formal administrative approval was taken before the start of the study by Qena Faculty of Medicine Ethical Committee of the study proposal. Approval from El-Zanaty and Ann [12] for using the raw data of DHS 2008 was obtained and security of the data was assured.

\section{Data management and analysis plan}

Data were analyzed using SPSS (version 16). Data analysis included descriptive statistics; frequencies, percentages, the mean and standard deviation. Then cross tabulations were performed. The differences in proportions among the groups were assessed using the Chi squared test; Continuous data were studied using the student T-test. The 5\% level was chosen as the level of significance and $95 \%$ confidence interval.

\section{Results}

As shown in Table 1, total number children (below 5 years of age) included in this study was 4,745 who distributed in 9 governorates of Upper Egypt as follows: Giza 10.5\%, Beni Suef 12.4\%, Fayoum 10.6\%, Menya $14.5 \%$, Assiut 14.4\%, Souhag 15.1\%, Qena 10.2\%, Aswan 6.5\% and Luxor $5.8 \%$. Personal data of the studied children are presented in Table 2 . This study included 4,745 children aged $<60$ months with the mean age \pm SD is $28.27 \pm 17.45$ months. Male children represented $51.1 \%$ while $48.9 \%$ were females. About three quarters were living in rural areas. Regarding the birth order, $27.6 \%$ were the first child and $41.9 \%$ were the second or third child. Table 3 and Figure 1 show that $40.1 \%$ of their mothers had no education compared to $22.4 \%$ the fathers, while $42.0 \%$ of the mothers and about half of the fathers completed at least the secondary level. The vast majority of the mothers were housewives and $5.0 \%$ of them were professionals. More than one quarter of the fathers were skilled workers, $21.1 \%$ were agricultural workers, $18.6 \%$ were professionals and $16.5 \%$ of them worked in sales and services. It was found that $38.7 \%$ of the parents were poorest according to the wealth index. Among 4,745 children under 5 years, 891 suffered from cough during the two-week before the survey with a prevalence of $18.8 \%$. Less than three quarters of them had experienced short or rapid breathing as

\begin{tabular}{|l|c|c|}
\hline Governorate & No. $(\mathbf{n = 4 7 4 5})$ & \% \\
\hline Giza & 496 & 10.5 \\
\hline Beni Suef & 590 & 12.4 \\
\hline Fayoum & 504 & 10.6 \\
\hline Menya & 688 & 14.5 \\
\hline Assuit & 685 & 14.4 \\
\hline Souhag & 718 & 15.1 \\
\hline Qena & 482 & 10.2 \\
\hline Aswan & 309 & 6.5 \\
\hline Luxor & 273 & 5.8 \\
\hline
\end{tabular}

Table 1: Distribution of the studied children in the Upper Egypt Governorates [12].

\begin{tabular}{|c|c|c|}
\hline Item & No. $(n=4745)$ & $\%$ \\
\hline \multicolumn{3}{|c|}{ Age group (months) } \\
\hline Less than 6 & 529 & 11.1 \\
\hline $6-$ & 553 & 11.7 \\
\hline $12-$ & 959 & 20.2 \\
\hline $24-$ & 926 & 19.5 \\
\hline $36-$ & 889 & 18.7 \\
\hline $48-59$ & 889 & 18.7 \\
\hline Mean \pm SD & \multicolumn{2}{|c|}{$28.27 \pm 17.45$} \\
\hline \multicolumn{3}{|l|}{ Sex } \\
\hline Male & 2424 & 51.1 \\
\hline Female & 2321 & 48.9 \\
\hline \multicolumn{3}{|l|}{ Religion } \\
\hline Muslim & 4410 & 92.9 \\
\hline Christian & 335 & 7.1 \\
\hline \multicolumn{3}{|l|}{ Residence } \\
\hline Urban & 1233 & 26 \\
\hline Rural & 3512 & 74 \\
\hline \multicolumn{3}{|l|}{ Birth order } \\
\hline First & 1310 & 27.6 \\
\hline Second or third & 1989 & 41.9 \\
\hline Fourth or fifth & 908 & 19.2 \\
\hline Sixth or more & 868 & 18.9 \\
\hline
\end{tabular}

Table 2: Personal characteristics of the studied children [12].

\begin{tabular}{|c|c|c|}
\hline Item & No. $(n=4745)$ & $\%$ \\
\hline \multicolumn{3}{|l|}{ Mother's occupation } \\
\hline Housewife & 4252 & 89.6 \\
\hline Professional & 236 & 5 \\
\hline Clerical & 43 & 0.9 \\
\hline Sales and services worker & 73 & 1.5 \\
\hline Agricultural worker & 99 & 2.1 \\
\hline Skilled manual worker & 10 & 0.2 \\
\hline Unskilled manual worker & 32 & 0.7 \\
\hline \multicolumn{3}{|l|}{ Father's occupation } \\
\hline Professional & 883 & 18.6 \\
\hline Clerical & 149 & 3.1 \\
\hline Sales and services worker & 871 & 16.5 \\
\hline Agricultural worker & 1000 & 21.1 \\
\hline Skilled manual worker & 1257 & 26.5 \\
\hline Unskilled manual worker & 532 & 11.2 \\
\hline Not work & 77 & 1.6 \\
\hline Don't know & 66 & 1.4 \\
\hline \multicolumn{3}{|l|}{ Wealth index } \\
\hline Poorest & 1836 & 38.7 \\
\hline Poorer & 1210 & 25.5 \\
\hline Middle & 787 & 16.6 \\
\hline Richer & 462 & 9.7 \\
\hline Richest & 450 & 9.5 \\
\hline
\end{tabular}

Table 3: Partners sociodemographic characteristics of the studied children [12].

a result of chest problem only (33.4\%), or nose problem only (14.4\%). More than half of the studied children suffered from both nose and chest-related problem at the same time. It was found that $11.3 \%$ of the studied children had chest-related ARI symptoms (Table 4). In Table 5, there is statistically significant difference between the diseased children and the other children in Upper Egypt regarding children age and sex. The children who had chest related infections had mean age \pm SD less than the children without respiratory tract infection $(24.06 \pm 17.48$ and $28.72 \pm 17.45$, respectively) (Figure 2 ) and most frequently among children aged 6 to 23 months. Male children and urban residents were the most likely had the symptoms. Table 6 shows that there are 


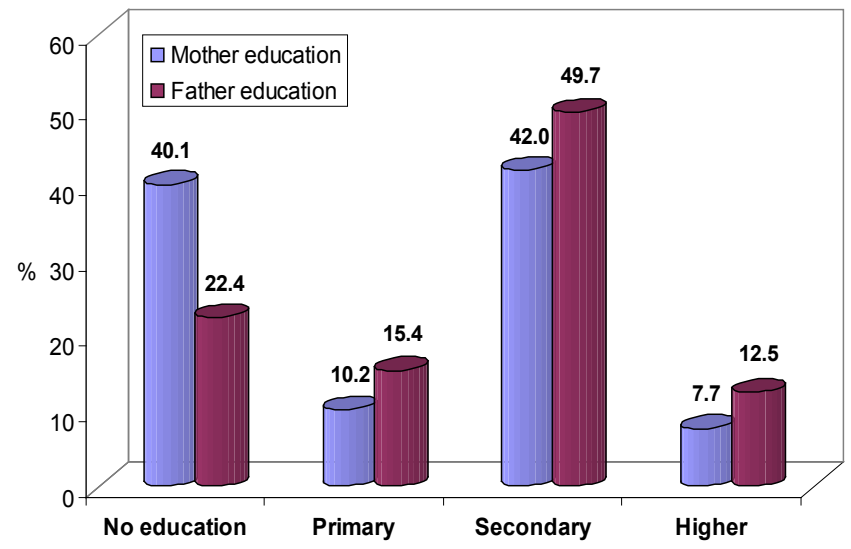

Figure 1: Educational level of the studied children parents [12].

\begin{tabular}{|l|c|c|}
\hline \multicolumn{2}{|l|}{ No. (n=4745) } & $\%$ \\
\hline Had cough in last two weeks & 891 & 18.8 \\
\hline Yes & 3854 & 81.2 \\
\hline No & 638 & \\
\hline Short, rapid breaths (n=891) & 245 & 71.6 \\
\hline Yes & 8 & 27.5 \\
\hline No & & \\
\hline Don't know & 213 & 33.4 \\
\hline The cause of the difficult breaths (n=638) & 92 & 14.4 \\
\hline Chest-related problem only & 325 & 50.9 \\
\hline Blocked/runny nose only & 8 & 1.3 \\
\hline Both blocked/runny nose and chest-related problem & $\mathbf{5 3 8}$ & 11.3 \\
\hline Don't know & & \\
\hline Symptoms of chest related ARI & & \\
\hline
\end{tabular}

Table 4: Distribution of the studied children by cough and related symptoms [12].

\begin{tabular}{|c|c|c|c|c|c|}
\hline \multirow[t]{3}{*}{ Item } & \multicolumn{4}{|c|}{ Children had chest related infections } & \multirow[t]{3}{*}{ P-value } \\
\hline & \multicolumn{2}{|c|}{ Yes $(n=538)$} & \multicolumn{2}{|c|}{ No $(n=4207)$} & \\
\hline & No. & $\%$ & No. & $\%$ & \\
\hline \multicolumn{6}{|c|}{ Age group (months) } \\
\hline Less than 6 & 57 & 10.8 & 472 & 89.2 & \multirow[t]{6}{*}{$0.000^{*}$} \\
\hline $6-$ & 101 & 18.3 & 452 & 81.7 & \\
\hline $12-$ & 142 & 14.8 & 817 & 85.2 & \\
\hline $24-$ & 81 & 8.7 & 845 & 91.3 & \\
\hline $36-$ & 76 & 8.5 & 813 & 91.5 & \\
\hline $48-59$ & 81 & 9.1 & 808 & 90.9 & \\
\hline Mean \pm SD & \multicolumn{2}{|c|}{$24.75 \pm 17.06$} & \multicolumn{2}{|c|}{$28.72 \pm 17.45$} & $0.000^{*}$ \\
\hline \multicolumn{6}{|l|}{ Sex } \\
\hline Male & 304 & 12.5 & 2120 & 87.5 & \multirow[t]{2}{*}{$0.008^{*}$} \\
\hline Female & 234 & 10.1 & 2087 & 89.9 & \\
\hline \multicolumn{6}{|l|}{ Religion } \\
\hline Muslim & 500 & 11.3 & 3910 & 88.7 & \multirow[t]{2}{*}{0.998} \\
\hline Christian & 38 & 11.3 & 297 & 88.7 & \\
\hline \multicolumn{6}{|l|}{ Residence } \\
\hline Urban & 162 & 13.1 & 1071 & 86.9 & \multirow[t]{2}{*}{$0.020^{*}$} \\
\hline Rural & 376 & 10.7 & 3136 & 89.3 & \\
\hline \multicolumn{6}{|l|}{ Birth order } \\
\hline First & 148 & 11.3 & 1162 & 88.7 & \multirow[t]{4}{*}{0.972} \\
\hline Second or third & 223 & 11.2 & 1766 & 88.8 & \\
\hline Fourth or fifth & 107 & 11.8 & 801 & 88.2 & \\
\hline Sixth or more & 60 & 11.2 & 478 & 88.8 & \\
\hline
\end{tabular}

Table 5: The relationship between occurrence of chest related infections and the personal characteristics of the studied children [12].

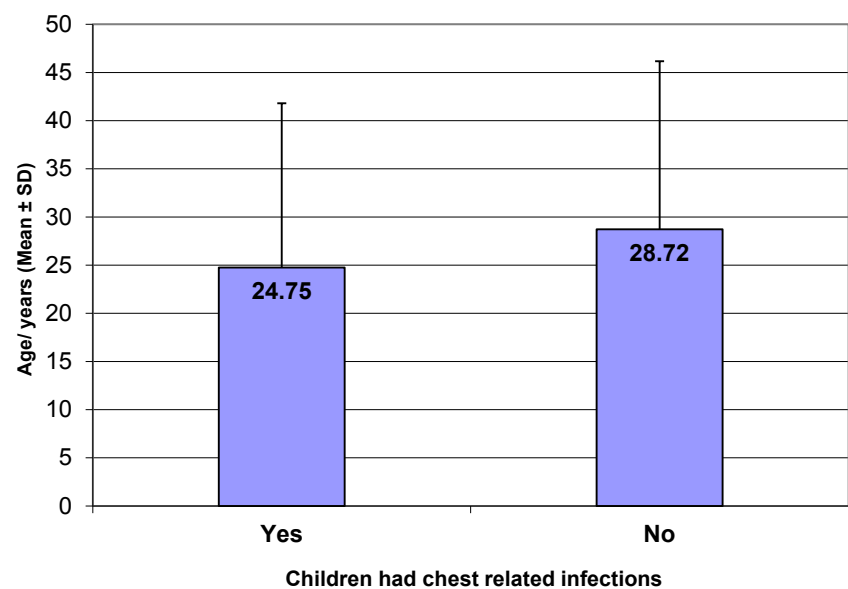

Figure 2: The relationship between the occurrence of chest related infections and the studied children mean age [12].

\begin{tabular}{|c|c|c|c|c|c|}
\hline \multirow[t]{3}{*}{ Item } & \multicolumn{4}{|c|}{ Children had chest related infections } & \multirow[t]{3}{*}{ P-value } \\
\hline & \multicolumn{2}{|c|}{ Yes $(n=538)$} & \multicolumn{2}{|c|}{ No $(n=4207)$} & \\
\hline & No. & $\%$ & No. & $\%$ & \\
\hline \multicolumn{6}{|c|}{ Mother educational level } \\
\hline No education & 191 & 10 & 1714 & 90 & \multirow[t]{4}{*}{0.116} \\
\hline Primary & 60 & 12.4 & 423 & 87.6 & \\
\hline Secondary & 239 & 12 & 1754 & 88 & \\
\hline Higher & 48 & 13.2 & 316 & 86.8 & \\
\hline \multicolumn{6}{|c|}{ Father educational level } \\
\hline No education & 95 & 8.9 & 967 & 91.1 & \multirow[t]{4}{*}{$0.040^{*}$} \\
\hline Primary & 92 & 12.6 & 640 & 87.4 & \\
\hline Secondary & 284 & 12 & 2076 & 88 & \\
\hline Higher & 67 & 11.3 & 524 & 88.7 & \\
\hline \multicolumn{6}{|l|}{ Mother's working } \\
\hline Working for cash & 70 & 14.6 & 411 & 85.4 & \multirow[t]{2}{*}{$0.018^{*}$} \\
\hline Housewife & 467 & 11 & 3796 & 89 & \\
\hline \multicolumn{6}{|l|}{ Wealth index } \\
\hline Poorest & 209 & 11.4 & 1627 & 88.6 & \multirow[t]{5}{*}{0.133} \\
\hline Poorer & 115 & 9.5 & 1095 & 90.5 & \\
\hline Middle & 102 & 13 & 685 & 87 & \\
\hline Richer & 55 & 11.9 & 407 & 88.1 & \\
\hline Richest & 57 & 12.7 & 393 & 87.3 & \\
\hline
\end{tabular}

Table 6: The relationship between occurrence of chest related infections and the studied children family background [12].

statistically significant differences between children who had chest related infections and those had not regarding parents' educational level and the mothers' work. The least proportion of diseased children was reported by mothers who had no education also among fathers without education ( $10.0 \%$ and $8.9 \%$, respectively).

\section{Discussion}

Secondary analysis of large data sets aids researchers to answer questions that would expensive and time-consuming to study [13]. However, it has considerable disadvantages such as you did not choose the study population and you cannot assess causality [14]. Analysis of Demographic Health Survey (DHS) data provides in-depth understanding of child health in Egypt. In the present study $18.8 \%$ suffered from cough. It is more than the prevalence of ARI among the national representative sample of children under 5 years who included in DHS 2008 which was $13.4 \%$ [12]. It is less than in that reported by 
El-Zanaty [9] in DHS 2014 (27.3\%). The prevalence of chest-related ARI symptoms was $11.3 \%$ among children of Upper Egypt that is more than the national figure (7.8\%) that peaks at $12 \%$ in Upper Egypt that reported by El-Zanaty and Ann [12] and $13.6 \%$ as national figure and the highest in rural Upper Egypt (15\%) which reported by El-Zanaty [9]. These findings may be contributed to the prevalence of ARI is usually encouraged by poor housing, overcrowding and low socio-economic factors which more common in the less privileged governorates of Upper Egypt. This prevalence is lower than that reported by Islam et al. [15] in India as the prevalence of ARI was $26.2 \%$. A cross-sectional study from Brazil reported that ARI in children under-five was $25.6 \%$ [16]. On the other hand, the prevalence in this study is higher than the prevalence reported in other studies. A study from Delhi reported that $14.6 \%$ in all surveyed under -five children, had an attack of ARI in the preceding 15 days [17] and $6.9 \%$ in another study [7]. In the present study, 6 to 23 months was more frequently affected age group. The age of complementary feeds introduction, decreasing breast feeding and decreasing of passive maternal immunity. This finding is similar to that found by Ujunwa et al. [18] who found that the age group affected with ARI most was 10-19 months. Montasser et al. [6] conducted a study for assessment and classification of acute respiratory tract infections among Egyptian rural children and found that the proportion of ARIs significantly reached its peak below 36 months then decreased with increasing of age of child [6]. This in agreement with the result found by Siziya et al. [7]. It was found that male children were more likely had the symptoms than female children (20.0\% versus $17.6 \%)$. This finding is the same as the results of other studies. For example, in Iraq male children were more infected with ARI than females. They were 1.5 times more likely to develop ARIs than females [5]. Also, Yadav et al. [19] found that male sex was significantly more in ARI cases in Nepal. This study showed that there is statistically significant difference regarding the residence as more than one fifth of the urban children suffered from ARIs compared to $18.3 \%$ of the rural children. This may because of a greater health seeking behavior among the urban families than the rural ones. This is also reported by Ujunwa et al. [18] who found that more of the subjects with ARI were from the urban areas. But Yadav et al. [19] found statistically significant association between ARI cases and rural environment.

In the present study, the least proportion of diseased children was reported by mothers who had no education also among fathers without education. This is may be explained by the lack of knowledge about ARI among the Egyptian community and the most of illiterate mothers were not able to recognize the symptoms and signs of ARI. Parental education specially mother's education helps to proper recognition of the disease and early health-care providers consultation. This has also been reported by Sreeramareddy et al. [20] in Nepal. The wealth index allows researchers to identify how much household economic status affects health outcomes. In this study the economic status is not an important risk factor for ARI. The data showed no obvious differences in the period prevalence between children from households in the different wealth quintiles. This is also reported by the World Bank [21]. This is may be explained as the Wealth Index is crude measure of illness reporting potentially points to health-seeking behavior and quality of care in Upper Egypt.

\section{Limitations of the Study}

There are some limitations should be considered the prevalence of ARI varies from summer to the winter, and the interviews in EDHS were conducted from March to May 2008. The data are subject to recall bias although the short period (two weeks) reduces such error. The researcher did not choose the study population and cannot assess causality. The data were only available for children whose mothers were in the reproductive age group and were alive. There are no reliable recent estimates of the proportion of children whose mother is not alive, but it is likely that such children are more vulnerable to illness and may also have more limited access to health services. The main limitation of this study is that interviewing children's mothers without any direct evaluation, makes the diagnosis of ARI depend on the mother reports that may affects the results.

\section{Conclusion and Recommendations}

There is statistically significant difference between the diseased children and the other under 5 children in Upper Egypt regarding children age and sex, residence, mothers and fathers educations. Improving the socio-economic lives of the individuals; hence helping in avoidance of some of the risk factors responsible for acute respiratory tract infections. Raising female literacy level can be help in prevention of morbidity among children.

\section{Ethical Approval}

Due to ethical implications associated with research involving vulnerable participants, medical record review is a useful method for exploring questions in pediatric research.

Formal administrative approvals were taken before the start of the study. These approvals included those obtained from the Ethical Committee of Faculty of Medicine, South Valley University for the study proposal and the Directorate of Assiut Children University Hospitals. Privacy and confidentiality of data were assured. The data collecting software did not capture patients' names.

\section{Acknowledgments}

Thanks are extended to Fatma El-Zanaty and her associates Egypt, the staff of Macro International Inc., and responded Egyptian women.

\section{Authors contribution}

Ahmed E Ahmed: Conception and design, literature review, acquisition of data and analysis, drafting the article, and final approval of the version published.

Ekram M Abdel Khalek: Conception and design, literature review, interpretation of data, and major contribution to the writing of the paper and final approval of the version published. and correspondence for the publication.

Ahmed H Kamel Marzok: Conception and design, literature review acquisition of data and analysis, drafting the article.

\section{References}

1. Simoes EF, Cherian T, Chow J, Shahid-Salles SA, Laxminarayan R, et al. (2006) Disease control priorities in developing countries. $2^{\text {nd }}$ edn. National Center for Biotechnology Information, National Library of Medicine 8600 Rockville Pike Bethesda MD, USA.

2. Nair GB, Niederman MS (2011) Community-acquired pneumonia: an unfinished battle. Med Clin North Am 95: 1143-1161.

3. Lanata CF, Rudan I, Boschi-Pinto C, Tomaskovic L, Cherian T, et al. (2004) Methodological and quality issues in epidemiological studies of acute lower respiratory infections in children in developing countries. Int J Epidemiol 33 1362-1372.

4. Johnson A (2007) Acute respiratory infections. Paediatrics and Child Health in Tropical Region. $2^{\text {nd }}$ edn. Owerri African Educational Services, pp: 396-425.

5. Yousif T, Khaleq BA (2006) Epidemiology of acute respiratory tract infections (ARI) among children under five years old attending Tikrit General Teaching Hospital. Middle East J Family Med 14: 148-152.

6. Montasser N, Helal R, Rezq R (2012) Assessment and classification of acute respiratory tract infections among Egyptian rural children. $\mathrm{Br} \mathrm{J}$ Med Med Res 2: 216-227.

7. Siziya S, Muula A, Rudatsikira E (2009) Diarrhoea and acute respiratory 
Citation: El-Abd Ahmed A, Abdel Khalek EM, Kamel MarzokAH (2016) Prevalence and Determinants of Chest-Related Symptoms of Acute Respiratory Tract Infections among Children below 5 Years in Upper Egypt. J Pulm Respir Med 6: 366. doi: 10.4172/2161-105X.1000366

infections prevalence and risk factors among under-five children in Iraq in 2000. Ital J Pediatr 25: 35-38.

8. Koch A, Mølbak K, Homøe P, Sørensen P, Hjuler T, et al. (2003) Risk Factors for acute respiratory tract infections in young Greenlandic children. Am J Epidemiol 158: 374-384.

9. El-Zanaty F (2015) Egypt Demographic and Health Survey 2014. Ministry of Health, Cairo, Egypt.

10. WHO (1999) Pneumococcal Vaccines. World Health Organization position paper. Weekly Epidemiological Records 74: 177-183.

11. WHO (2000) Technical seminar-Acute respiratory infections. Department of Child and Adolescent Health and Development (CAH), World Health Organization, Geneva.

12. El-Zanaty F, Ann W (2009) Egypt Demographic and Health Survey 2008 Ministry of Health, Cairo, Egypt.

13. Mainous AG, Hueston WJ (1997) Using other people's data: the ins and outs of secondary data analysis. Family Med 29: 568-571.

14. Smith A, Ayanian J, Covinsky K, Landon B, McCarthy E, et al. (2011) Conducting high-value secondary dataset analysis: an introductory guide and resources. J Gen Intern Med 26: 920-929.
15. Islam F, Sarma R, Debroy A, Kar S, Pal R (2013) Profiling Acute Respiratory Tract Infections in Children from Assam, India. J Glob Infect Dis 5: 8-14.

16. Duarte D, Botelho $C$ (2000) Clinical profile of children under 5 years of age with acute respiratory tract infections. J Pediatr (Rio J) 76: 207-212.

17. Gupta N, Jain SK, Ratnesh, Chawla U, Hossain S, et al. (2007) An evaluation of diarrheal diseases and acute respiratory infections control programmes in a Delhi slum. Indian J Pediatr 74: 471-476.

18. Ujunwa FA, Ezeonu CT (2014) Risk factors for acute respiratory tract infections in under-five children in Enugu Southeast Nigeria. Ann Med Health Sci Res 4 95-99.

19. Yadav S, Khinchi Y, Pan A, Gupta SK, Shah GS, et al. (2013) Risk factors for acute respiratory infections in hospitalized under five children in Central Nepal. J Nepal Paediatr Soc 33: 39-44.

20. Sreeramareddy CT, Shankar RP, Sreekumaran BV, Subba SH, Joshi HS, et al. (2006) Care seeking behaviour for childhood illness-A questionnaire survey in western Nepal. BMC Int Health Hum Rights 6: 7.

21. The World Bank (2012) Health equity and financial protection data sheet-Egypt. DC: World Bank. Washington, USA 